\title{
OBSERVACIONES SOBRE LA VALIDEZ DEL CONCEPTO PURO DE DERECHO EN GRUNDLAGE DES NATURRECHTS (1796/97) DE J. G. FICHTE
}

\section{Luciano Florencio Corsico ${ }^{1}$}

\begin{abstract}
Resumen
La relación entre ética y derecho dentro de la filosofía de Fichte es ciertamente problemática. Por un lado, la doctrina ética de Fichte se basa en un principio con validez absoluta e incondicionada. Tal como sucede en la filosofía crítica de Kant, la ley moral adquiere para Fichte la forma de un imperativo categórico, que exige su cumplimiento a todos los seres racionales en cualquier condición o circunstancia. La doctrina fichteana del derecho natural posee un fundamento distinto. El principio del derecho exige una relación recíproca entre seres racionales, donde cada uno sea capaz de limitar su propia libertad en favor de la posible libertad del otro. En una primera instancia, Fichte afirma que la validez de este principio es sólo hipotética, porque únicamente depende de la previa decisión individual de vivir dentro de una comunidad. Sin embargo, el propio Fichte admite luego que es casi imposible concebir una vida humana fuera de las relaciones intersubjetivas dentro de la comunidad. La necesaria relación entre el individuo y la comunidad es un presupuesto fundamental de la filosofía de Fichte. A partir de este presupuesto pueden derivarse importantes consecuencias teóricas. Si un ser racional sólo puede considerarse como tal en el contexto de una comunidad (cuando esa comunidad está fundada en el derecho), también debería adjudicarse al principio del derecho una validez categórica.
\end{abstract}

Palabras clave: derecho, individuo, comunidad, validez hipotética, validez categórica.

\section{INTRODUCCIÓN}

No cabe dudas de que la filosofia del derecho ocupa un lugar de enorme importancia dentro del sistema filosófico de J. G. Fichte, que recibe el nombre de Doctrina de la Ciencia (WL). Durante su período de Jena (1794-1799), Fichte expone básicamente los principios fundamentales de este sistema filosófico en tres escritos: Grundlage der gesammten Wissenschaftslehre de 1794/95, Grundlage des Naturrechts de 1796/97 y Das System der Sittenlehre de $1798 .^{2}$ Hacia el final del período de Jena, Fichte concibe además una nueva

\footnotetext{
${ }^{1}$ Doctor en Filosofía de la Universidad Nacional de Rosario (UNR). Actualmente, realiza una investigación postdoctoral sobre el derecho de coacción dentro del pensamiento jurídico-político de Fichte con financiamiento de CONICET. E-mail: corsicoluciano@yahoo.com

${ }^{2}$ Las referencias a los textos de J. G. Fichte utilizados en el presente trabajo corresponden siempre a la edición de sus obras completas contenidas en Gesamtausgabe der Bayerischen Akademie der Wissenschaften, Lauth, R. Jacob, H. y Gliwitzky, H. (eds.), Stuttgart/Bad Cannstatt: Frommann-Holzboog,1962 ss. En cada caso se utiliza la abreviatura GA, seguida por el número de volumen y la paginación correspondiente. A las citas del texto original en alemán ubicadas en el cuerpo del texto se añade siempre una traducción al español en una nota a pie de página. La versión en español corresponde siempre a la traducción de José Luis vol.08, no. 03, Rio de Janeiro, 2015.pp. 1481-1508 1481
} 
fundamentación de su sistema filosófico que se conoce con el nombre de Wissenschaftslehre nova methodo (1798/99). En este conjunto de escritos articulados por un mismo método de deducción, Fichte expone los fundamentos de su philosophia prima, de su doctrina ética y de su teoría del derecho. Esta teoría del derecho ocupa ciertamente un lugar destacado dentro de ese contexto sistemático. En su Grundlage des Naturrechts (GNR), Fichte intenta ofrecer una justificación racional del concepto de derecho y de su necesaria relación con la autoconciencia del individuo. Dicho con otras palabras, Fichte pretende mostrar en ese escrito que el concepto de derecho es un presupuesto necesario en la autoconciencia de todo ser racional. Además de su importancia específica, el propio Fichte afirma que su deducción y exposición del concepto de derecho mantiene una cierta autonomía con respecto a las demás doctrinas que forman parte de su sistema filosófico, fundamentalmente con respecto a su doctrina ética. ${ }^{3}$

En el presente trabajo, quisiera ocuparme de un tema relacionado precisamente a este vínculo entre ética y derecho dentro de la filosofía fichteana. La posición de Fichte sobre este vínculo no está libre de ambigüedades. A primera vista, Fichte parece trazar una profunda línea divisoria entre ambas disciplinas. A ambos lados de esa línea divisoria, se encontrarían la ética y el derecho como dos tipos de saber basados en principios totalmente diferentes. Por un lado, la doctrina ética de Fichte se basa en un principio con validez absoluta e incondicionada. Tal como sucede en la filosofía crítica de Kant, la ley moral adquiere para Fichte la forma de un imperativo categórico, que exige su cumplimiento a todos los seres racionales en cualquier circunstancia. Por otro lado, Fichte propone un fundamento distinto para su doctrina del derecho natural. El principio fichteano del derecho exige una relación recíproca entre seres racionales, donde cada uno sea capaz de limitar su libertad en favor de la posible libertad del otro. En una primera instancia, Fichte niega una validez categórica a este principio del derecho. En efecto, Fichte sostiene que la validez de este principio es sólo hipotética, porque únicamente depende de la previa decisión de un individuo de permanecer dentro de una comunidad. Es decir, la ley jurídica sólo exige obediencia a aquellos individuos que desean compartir su existencia con otros individuos en el espacio de una misma comunidad.

Sin embargo, el propio Fichte admite que es casi imposible pensar una vida humana fuera de esta trama de relaciones comunitarias. La necesaria relación entre el individuo y la comunidad es un presupuesto fundamental de la filosofía de Fichte. A partir de este presupuesto pueden derivarse importantes consecuencias

Villacañas Berlanga, Manuel Ramos Varela, y Faustino Oncina Coves en: Fichte, Johann Gottlieb, Fundamento del Derecho Natural según los Principios de la Doctrina de la Ciencia, Centro de Estudios Constitucionales, Madrid, 1994.

${ }^{3}$ En las últimas décadas, algunos estudios especializados se han ocupado precisamente de analizar la posibilidad de admitir una teoría del derecho independiente de una teoría ética dentro de la obra de Fichte. El carácter autónomo de la teoría fichteana del derecho de 1796/97 ha sido claramente enfatizado, por ejemplo, en el análisis de Alain Renaut. Según Renaut, el intento de Fichte de convertir la doctrina del derecho en una disciplina autónoma está muy claro ya desde la introducción de su GNR de 1796/97. Según Renaut, este intento de Fichte de elaborar una doctrina autónoma del derecho es incluso comparable a la "teoría pura del derecho" que formula Kelsen, casi un siglo y medio después (Renaut,1986). 
teóricas con respecto a la doctrina fichteana del derecho. Si un ser racional sólo puede considerarse como tal en el contexto de una comunidad fundada en el derecho, también debería adjudicarse al principio del derecho una validez categórica. El derecho me exigiría entonces reconocer al otro como un ser racional y libre de manera categórica, porque en última instancia nunca puedo pensarme a mí mismo aislado de la relación que mantengo con ese otro en el marco de una comunidad. De esta forma, el concepto del derecho no representa una exigencia meramente condicionada por una decisión contingente o por un deseo caprichoso, sino que se fundamenta necesariamente en una condición de posibilidad de mi propia autoconciencia como ser racional, a saber: en una necesaria relación intersubjetiva con los demás miembros de la comunidad. En efecto, puede observarse también que algunas afirmaciones de Fichte en su GNR de 1796/97 parecen confirmar precisamente la posibilidad de atribuir una validez categórica al principio del derecho dentro del marco de su filosofía trascendental. Ahora bien, si pudiese atribuirse al concepto de derecho una validez categórica, desaparecería un valioso criterio para distinguir entre el ámbito de la ética y el ámbito del derecho dentro de la filosofia de Fichte. Sin ese criterio, la supuesta independencia entre ética y derecho se volvería ciertamente problemática o, en todo caso, artificial. Por un lado, la ley moral sólo podría cumplirse y hacerse efectiva dentro del marco jurídico de una comunidad. Por otro lado, el derecho no sería otra cosa que la realización de esa misma ley moral en un mundo sensible compartido por seres racionales que interactúan entre sí.

Con el objetivo de desarrollar este tema con mayor claridad, divido mi exposición en tres secciones. La primera sección es la más extensa, porque intento ofrecer allí una reconstrucción de la deducción fichteana del concepto puro de derecho en GNR de 1796/97. Si un análisis exhaustivo de la deducción fichteana, que se desarrolla en tres núcleos argumentativos fundamentales, no sería posible comprender luego el significado del problema planteado en el presente artículo (1). La segunda sección estará dedicada al análisis de las afirmaciones de Fichte sobre la validez hipotética del concepto puro de derecho y su relación con la validez categórica de la ley moral (2). En la tercera sección, me ocupo de analizar las afirmaciones de Fichte sobre la estrecha dependencia entre comunidad e individuo, no sólo dentro de su teoría del derecho, sino también en algunos escritos previos de su período de Jena (3). Finalmente, expongo algunas conclusiones sobre el tema analizado. Según la concepción fichteana del hombre, no resulta tan evidente que su pertenencia a la comunidad sea susceptible de una decisión libre o contingente. El vínculo de reconocimiento con una comunidad de seres racionales parecen más bien originario y constitutivo del Yo, no una simple circunstancia externa que puede alterar según su propia voluntad. La pertenencia a esa comunidad humana es una condición necesaria para la autoconciencia individual. Ahora bien, si un Yo sólo puede existir como un ser racional dentro de una comunidad fundada en el derecho, y sólo puede cumplir en esa misma comunidad con las exigencias prácticas de la razón, entonces quizás pueda afirmarse que el principio del derecho no sólo tiene una validez hipotética, sino también categórica e incondicionada. 


\section{DEDUCCIÓN DEL CONCEPTO PURO DE DERECHO}

Como se ha señalado anteriormente, J. G. Fichte pretende demostrar en su Grundlage des Naturrechts (GNR) de 1796/97 que el concepto puro de derecho es un presupuesto necesario de la toda actividad racional y autoconsciente de un sujeto individual. Desde luego, la mencionada pretensión sólo puede ser sostenida sobre la base de un adecuado método de demostración y justificación. Inspirado por la filosofía crítica de Kant, Fichte adopta el método de la deducción trascendental. En su versión fichteana, este método deductivo implica una intuición de las propias acciones (que Fichte denomina intuición intelectual) y una reflexión sobre las condiciones de posibilidad de esas acciones.

Para alcanzar una fundamentación del concepto puro del derecho, Fichte desarrolla su deducción trascendental en tres etapas. En cada una de estas etapas de su argumentación, Fichte afirma un "teorema" (Lehrsatz) que expresa una pretensión de validez, y luego intenta ofrecer una demostración deductiva de esa pretensión. En la primera etapa, Fichte intenta demostrar que un ser racional finito no puede pensarse a sí mismo, sin atribuirse una actividad libre y eficiente en el mundo sensible. Según Fichte, el fundamento de esta actividad libre debe residir en el propio ser racional: sólo de esa forma puede comprenderse como una actividad dirigida racionalmente. En el prágrafo $\$ 1$ de su GNR, Fichte afirma:

Soll ein Vernunftwesen sich als solches setzen, so muß es sich eine Thätigkeit zuschreiben, deren letzter Grund schlechthin in ihm selbst liege. (Beides sind Wechselsätze: einer sagt, was der andere sagt.) In sich selbst zurückgehende Thätigkeit überhaupt (Ichheit, Subjectivität) ist Charakter des Vernunftwesens. Das Setzen seiner selbst (die Reflexion über sich selbst) ist ein Act dieser Thätigkeit. Diese Reflexion heisse A. Durch den Act einer solchen Thätigkeit setzt sich das Vernunftwesen. Alle Reflexion geht auf etwas, als auf sein Object, B. Was für ein Etwas muß denn das Object der geforderten Reflexion A seyn? Das Vernunftwesen soll in ihr sich selbst setzen, sich selbst zum Object haben. Aber sein Charakter ist in sich zurückgehende Thätigkeit. Das letzte höchste Substrat (B) seiner Reflexion auf sich selbst muß demnach auch seyn, in sich selbst zurückgehende, sich selbst bestimmende Thätigkeit. (GA I/3, 329). ${ }^{4}$

Fichte muestra en este pasaje el carácter eminentemente reflexivo de la actividad realizada por un ser racional. En efecto, cuando alguien se piensa a sí mismo como un ser racional, se atribuye necesariamente una actividad que no tiene su fundamento en un objeto externo, sino en él mismo. En tanto el fundamento de esta actividad se encuentra en la razón, se le atribuye también un carácter reflexivo. Si una actividad racional no fuera

\footnotetext{
4 "Si un ser racional debe ponerse como tal, entonces tiene que atribuirse una actividad, cuyo último fundamento reside absolutamente en él mismo (ambas son proposiciones intercambiables: la una afirma lo mismo que la otra). La actividad en general que regresa a sí misma (yoidad, subjetividad) es el carácter del ser racional. El ponerse a sí mismo (la reflexión sobre sí mismo) es un acto de esta actividad. Esta reflexión la llamo A. Por el acto de tal actividad se pone el ser racional. Toda reflexión apunta a algo como a su objeto, B. ¿Qué clase de algo tiene que ser el objeto de la reflexión A exigida antes? El ser racional debe ponerse a sí mismo en ella, debe tenerse a sí mismo como objeto. Pero su carácter es la actividad que regresa a sí. El último sustrato supremo B de su reflexión sobre sí mismo tiene que ser por tanto la actividad que regresa sobre sí misma, que se autodetermina" (Las cursivas pertenecen al texto original).
} 
reflexiva, el ser racional no podría adjudicársela. Este ser actuaría pero sin saber que actúa o, en todo caso, ignorando cuál es la naturaleza de sus acciones. O tal vez percibiría sus acciones, pero no sería capaz de comprender que son suyas. Si su actividad no fuese reflexiva, sino un simple accionar mecánico y ciego, entonces este ser racional tampoco se podría pensar o intuir a sí mismo como racional. Por ese motivo, Fichte argumenta que el ser racional debe tenerse a sí mismo como objeto de su pensamiento. En otras palabras, este ser puede comprenderse como un ser racional precisamente porque es capaz de esta actividad reflexiva, en la cual se tiene a sí mismo como objeto.

Por otra parte, Fichte afirma que el ser racional también debe ser capaz de distinguir en sí mismo dos actividades diferentes: la reflexión sobre sí mismo y la intuición de un mundo externo. En tanto sólo se dirige a sí misma, la actividad reflexiva debe oponerse a la intuición del mundo externo, como una actividad dirigida hacia algo diferente de ella misma. La actividad de intuir no debe dirigirse al propio intuyente, sino a un mundo, como un objeto contrapuesto a él (GA I/3, 330). La actividad del ser racional en su intuición del mundo está sometida al ser de los objetos. En la actividad intuitiva, pretendemos representarnos los objetos tal como son, sin ninguna intervención de nuestra parte. En este sentido, la actividad del Yo tiene que estar limitada y retenida, para que los objetos puedan ser verdaderamente representados (GA I/3, 330-331). La actividad reflexiva aparece, en cambio, como una actividad libre, que intenta eliminar toda relación vinculante con los objetos. Esta actividad reflexiva, explica Fichte, tiene que comprenderse como "un retornar del ser racional a sí mismo" (ein Zurückgehen des Vernunftwesens in sich selbst). Al mismo tiempo, ese retorno sobre sí mismo no es posible, si la actividad del ser racional se encuentra dirigida a los objetos. A diferencia de la actividad intuitiva o representativa, la actividad reflexiva no está condicionada por el ser de los objetos, sino que debe comprenderse como el fundamento de una actividad causal del ser racional sobre esos objetos (GAI/3, 331).

En otras palabras, Fichte argumenta que la intuición de los objetos es una actividad eficiente suprimida. En cambio, la actividad reflexiva de un ser racional debe finalmente dirigirse a su objeto para transformarlo. Es decir, la actividad reflexiva se relaciona indirectamente con el mundo externo, pero se relaciona directamente con el propio ser racional. Según Fichte, es necesario comprender la mencionada actividad reflexiva como "una libre autodeterminación a la actividad eficiente" (eine freie Selbstbestimmung zur Wirksamkeit) sobre el mundo sensible. Esto significa que, antes de efectuar una acción sobre el mundo sensible, el ser racional reflexiona sobre sí mismo y produce un concepto de fin de su acción eficiente. Según Fichte, sólo a través de esa actividad reflexiva, el ser racional adquiere una verdadera conciencia de sí mismo y de sus propias acciones. En este sentido, además, la autoconciencia del ser racional adquiere un significado esencialmente práctico. El Yo práctico y el Yo reflexivo se identifican, en la medida en que el Yo reflexiona sobre sus propias acciones. Dice Fichte: 
Es wird behauptet, daß das praktische Ich das Ich des ursprünglichen Selbstbewußtseyns sey; daß ein vernünftiges Wesen nur im Wollen unmittelbar sich wahrnimmt, und sich nicht, und dem zufolge auch die Welt nicht wahrnehmen würde, mithin auch nicht einmal Intelligenz seyn würde, wenn es nicht ein praktisches Wesen wäre. Das Wollen ist der eigentliche wesentliche Charakter der Vernunft; das Vorstellen steht mit demselben der Einsicht des Philosophen nach, freilich in Wechselwirkung, aber dennoch wird es gesetzt als das zufällige. Das praktische Vermögen ist die innigste Wurzel des Ich, auf dieses wird erst alles andere aufgetragen, und daran angeheftet. $(\mathrm{GAI} / 3,332)^{5}$

Según este pasaje, entonces, Fichte atribuye a la autoconciencia un carácter práctico. Fichte afirma aquí que el ser racional tiene una conciencia inmediata de su propia voluntad y adquiere una conciencia de sí mismo a través de la determinación de esa voluntad. Sin una previa determinación de su voluntad, el ser racional tampoco podría tener conciencia de sí mismo como una inteligencia representativa. La necesidad de una actividad representativa sólo surge a partir de una previa determinación de la voluntad para actuar de manera eficiente sobre el mundo sensible. En primer lugar, el Yo tiende originariamente a modificar el mundo. Como consecuencia de esa tendencia originaria, surge posteriormente en él la necesidad de representar el mundo de manera objetiva.

Además, Fichte sostiene que la autoconciencia siempre presupone un movimiento reflexivo. Un ser racional tiene que encontrar el fundamento de su actividad eficiente en sí mismo, y para eso debe reflexionar. En otras palabras, un ser autoconciente sólo equivale a un sujeto de una actividad reflexiva. A través de esta actividad, el ser racional puede encontrar en sí mismo el concepto de una finalidad de su acción eficiente. De acuerdo con este concepto, el ser racional puede luego realizar una acción en un mundo sensible fuera de él. También la actividad intuitiva se dirige al mundo sensible, pero no pretende modificarlo, sino únicamente conocerlo tal como es. Pero el ser racional puede descubrir en sí mismo el fundamento de otra actividad, que se dirige al mundo sensible para producir una modificación en él. Esta actividad ya no es teórica, sino esencialmente práctica. Cuando reflexiona sobre esa actividad, el sujeto se concibe a sí mismo como un Yo práctico, que encuentra en el uso de su razón el único fundamento de su propia actividad.

Según Fichte, la filosofía ha comprendido desde sus comienzos que existe un estrecho vínculo entre la representación y la voluntad. En efecto, ha sido generalmente admitida la idea de que la voluntad se encuentra condicionada por la representación, en el sentido de que estamos obligados a representar previamente ese objeto hacia el cual tiende luego nuestra voluntad. Sin embargo, explica Fichte, no ha sido igualmente frecuente la afirmación inversa de que toda representación se encuentra condicionada por la voluntad. En este aspecto reside la verdadera contribución de la Doctrina de la Ciencia como filosofía trascendental. Ella afirma que la

\footnotetext{
5 "Se afirma que el Yo práctico es el Yo de la autoconciencia originaria; que un ser racional sólo se percibe inmediatamente en el querer, y no se percibiría, y, en consecuencia, no percibiría el mundo, luego no sería ni siquiera inteligencia, si no fuera un ser práctico. El querer es el carácter esencial propio de la razón; según la intelección de los filósofos, el representar se halla con el mismo en una relación de acción recíproca, pero sin embargo es puesto como lo contingente. La facultad práctica es la raíz más íntima del Yo, sobre ella se apoyan todas y están prendidas a ella".
} 
representación no es posible, sin una previa referencia al sujeto representante y a su facultad práctica. Antes de representar un objeto de una cierta manera, el sujeto debe tener conciencia de sus acciones y de sí mismo como un Yo práctico. Como explica Fichte en su Ueber Geist und Buchstab in der Philosophie de 1794, un mismo objeto puede ser representado de distintas maneras según el interés práctico del sujeto. Según Fichte, ese interés práctico se determina previamente con absoluta espontaneidad, antes de toda representación. Por ese motivo, la misma estrella puede ser representada por un astrónomo como un cuerpo celeste sometido a leyes inmutables y por el campesino como una fuente de iluminación que le permite recoger sus herramientas de labranza en medio de la noche (GA I/6, 340). De este modo, es posible entender la afirmación de Fichte, según la cual la simple inteligencia no es suficiente para constituir un ser racional (GA I/3, 333). La característica básica del punto de vista trascendental consiste en concebir al Yo como un ser que actúa y que determina previamente su voluntad de acuerdo a un fin. La filosofía trascendental exige luego a cada uno que pueda captarse a sí mismo como una identidad entre la acción y el producto resultante de esa acción (GAI/3, 334).

Desde luego, frente al Yo práctico que determina sus propios fines, aparece un mundo sensible, que existe independientemente del Yo. Es decir, el ser racional no puede pensarse a sí mismo como un ser activo, sin representar al mismo tiempo un objeto al cual dirige su acción. Ese objeto pertenece al mundo externo, como sistema total de objetos (GA I/3, 337). La necesidad de admitir un mundo real fuera del Yo no se funda en la facultad teórica del Yo, sino en su facultad práctica. En verdad, explica Fichte, si únicamente consideramos el ejercicio de nuestra facultad representativa, efectivamente pueden surgir numerosas dudas sobre la existencia de cosas fuera de nosotros. Esta duda escéptica aparece justamente en el contexto del idealismo dogmático, que excluye por completo la "actividad práctica" (praktische Thätigkeit) del campo de sus investigaciones. El idealista dogmático considera de manera puramente especulativa la facultad representativa de un sujeto y su posible conexión con el mundo externo. En el marco de esa especulación tan restringida, es posible ciertamente admitir alguna duda escéptica sobre la existencia del mundo. Sin embargo, ningún idealista dogmático ha conseguido extender esas mismas dudas hasta el ámbito de la acción. En el ámbito de la actividad práctica, nadie puede dudar seriamente de la existencia del mundo externo, porque entonces quedaría completamente privado de la posibilidad de actuar. El mundo externo es así el presupuesto necesario de la acción y no de la representación. El idealista trascendental puede así afirmar la existencia del mundo externo, porque su reflexión abarca al mismo tiempo la actividad teórica y práctica del Yo (GA I/3, 338).

A través de esta primera secuencia de argumentación, entonces, Fichte intenta demostrar que un ser racional finito no puede ponerse a sí mismo, sin atribuirse al mismo tiempo una actividad eficiente en el mundo sensible. En otras palabras, cuando alguien pretende pensarse a sí mismo como un ser racional, está obligado a admitir que ejerce una actividad eficiente y que produce modificaciones en el mundo externo. El ejercicio de esa 
actividad debe estar sometido siempre a la reflexión del propio ser racional y debe tener su fundamento en la libre autodeterminación. Como se ha visto, la finalidad de la acción debe tener su fundamento en el propio ser racional y no en un objeto del mundo externo. Pero, además, esa actividad debe ser capaz de producir algún efecto. Según Fichte, la reflexión sobre esa actividad es un presupuesto necesario de la autoconciencia de un ser racional finito. Un ser racional no se hace consciente de sí mismo a través de la mera representación de los objetos del mundo externo. En el conocimiento objetivo, el sujeto sólo es consciente del objeto representado y no de su propia actividad. Un ser racional finito sólo adquiere conciencia de sí mismo, cuando se piensa como un ser que actúa sobre el mundo sensible y lo modifica. En sentido estricto, ese ser racional sólo puede conocer su actividad eficiente de manera reflexiva. A través de la intuición sensible puede conocer las modificaciones que produce en el mundo por medio de su acción, pero sólo la reflexión le permite descubrir que él mismo es la causa de esas modificaciones. Por esa razón, la reflexión sobre su actividad eficiente sobre el mundo es también un presupuesto de su autoconciencia individual.

En la segunda etapa de su deducción trascendental del concepto de derecho, Fichte intenta probar que el ser racional finito no puede atribuirse una actividad eficiente en el mundo sensible, sin atribuirla también a otros seres finitos fuera de él. Tal como argumenta Fichte en la primera parte de su deducción, la actividad del ser racional debe ser libre y autodeterminada. No puede estar causalmente determinada por un objeto material del mundo externo. Según Fichte, el sujeto no puede encontrarse "forzado" (genöthigt) a actuar en general, porque entonces no podría pensarse como un Yo libre. Tampoco puede encontrarse forzado a actuar de esta o aquella manera (GA I/3, 343). Sin embargo, el ser racional finito sólo puede convertirse en autoconciente si se determina a actuar sobre el mundo externo. En este sentido, la autoconciencia de un individuo (como ser racional finito) parece estar condicionada por la posibilidad de referir su actividad hacia algún objeto. Por ese motivo, como también se ha visto, la autoconciencia individual no sólo presupone la actividad reflexiva, sino también una actividad dirigida hacia un objeto del mundo externo. Ahora bien, ese objeto no puede pertenecer al mismo sujeto, en tanto debe representar un verdadero límite para su actividad subjetiva. Fichte intenta mostrar entonces que la actividad del ser racional finito debe estar limitada por un objeto, pero ese objeto no debe anular tampoco su libertad o su capacidad de autodeterminación.

Surge así un problema para conciliar la actividad libre de un ser racional y su limitación por medio de un objeto externo. En este punto, parece necesario elegir entre dos alternativas opuestas: o bien se comprende a ese ser racional como un ser que actúa con libertad y autodeterminación; o bien se admite que su libertad se encuentra limitada por un objeto externo y sus acciones son determinadas por este último. Para resolver este problema sin eliminar completamente ninguna de las alternativas mencionadas, Fichte introduce el concepto de "exhortación" (Aufforderung). Según Fichte, el concepto de exhortación designa una influencia externa sobre el 
sujeto, pero que no suprime su libertad o su capacidad de autodeterminación. En virtud de una exhortación, se efectúa una determinación del sujeto a la autodeterminación libre de sus propias acciones (GA I/3, 342). Para conservar su carácter objetivo y representar de este modo una limitación de la propia actividad, esta influencia sobre el sujeto debe ser intuida como una influencia procedente del exterior. Pero, a su vez, si se pretende evitar una negación de la libertad del sujeto, entonces esa influencia sólo puede comprenderse como una mera exhortación del sujeto para actuar (GA I/3,342).

En tanto el sujeto se comprende a sí mismo, posee el concepto de su propia libertad y espontaneidad. Sin embargo, Fichte sostiene que esa comprensión de la propia libertad individual para actuar está condicionada por una exhortación que procede de otro ser racional. Fichte sugiere, además, que el concepto de una actividad libre no tiene un sentido descriptivo, porque no designa algo que existe "en el momento presente" (im gegenwärtigen Momente). El concepto de una actividad libre (a la cual el sujeto individual es exhortado) tiene más bien un sentido normativo, en la medida en que se refiere siempre a una actividad que debe realizarse en el futuro (GA I/3 342-343). Es decir, la exhortación no cumple la función de comunicarle o informarle a un ser racional que realiza en la actualidad una acción con total libertad, sino que le exige la realización futura de esa acción.

El sujeto recibe entonces una exhortación a actuar libremente. Esa exhortación representa una "exigencia" (Anforderung): el ser racional debe realizar su libre actividad causal (GA I/3, 343). Según Fichte, el sujeto a quien se dirige esta exhortación puede cumplirla de dos maneras distintas. Por un lado, el sujeto puede cumplir con la exhortación "a través de un actuar efectivo" (durch wirkliches Handeln). En tanto actúa, el sujeto decide actuar de un modo determinado. Dentro de la esfera de todas sus acciones posibles, el sujeto es exhortado a elegir una acción determinada a través de una absoluta autodeterminación. De este modo, el sujeto que realiza una acción determinada conserva su carácter de ser racional y libre, pero cumple también con la exhortación recibida (GA I/3, 343). Por otro lado, Fichte señala también que el sujeto puede cumplir con esa misma exhortación "a través de un no-actuar" (durch Nichthandeln). Esto significa que el sujeto conserva su racionalidad y su libertad también cuando decide no realizar ninguna acción, porque esa decisión presupone la previa comprensión de su propia actividad causal como algo exigido de él. Aunque el sujeto pueda proceder contra la expectativa de actuar de manera efectiva, cumple sin embargo con la exigencia de autodeterminarse libremente. Cuando se abstiene de realizar una determinada acción, el sujeto también decide con total libertad entre actuar y no actuar $(\mathrm{GAI} / 3,343)$.

Ahora bien, la exhortación recibida por el sujeto debe ser intuida como una "influencia” (Einwirkung) externa y tiene que representar entonces una limitación de la actividad de ese sujeto. En efecto, Fichte argumenta que toda intuición externa, como opuesta a la actividad reflexiva, supone una limitación del Yo. Pero no es posible pensar un límite, sin algo que tenga la facultad de limitar. Según Fichte, es posible extraer esta conclusión a partir 
de la reflexión sobre la propia actividad, según las leyes necesarias del ser racional $(\mathrm{GA} \mathrm{I} / 3,344)$. Es decir, cuando un sujeto reflexiona sobre su propia actividad y admite una limitación, como condición de su autoconciencia individual, debe admitir también algo fuera de él que determina ese límite. Este ser determinante fuera del sujeto debe comprenderse igualmente como un ser racional y libre, porque su única forma de influjo consiste en la exhortación a una acción autodeterminada. Dice Fichte:

Die Aufforderung ist die Materie des Wirkens, und eine freie Wirksamkeit des Vernunftwesens, an welche sie ergeht, sein Endzweck. Das letztere soll durch die Aufforderung keinesweges bestimmt, necessirt werden, wie es im Begriffe der Causalität das Bewirkte durch die Ursache wird, zu handeln; sondern es soll nur zufolge derselben sich selbst dazu bestimmen. Aber soll es dies, so muß es die Aufforderung erst verstehen und begreifen, und es ist auf eine vorhergehende Erkenntniß desselben gerechnet. Die gesetzte Ursache der Aufforderung ausser dem Subjecte muß demnach wenigstens die Möglichkeit voraussetzen, dass das letztere verstehen und begreifen könne, ausserdem hat seine Aufforderung gar keinen Zweck. Die Zweckmäßigkeit derselben ist durch den Verstand und das Freiseyn des Wesens, an welches sie ergeht, bedingt. Diese Ursache muß daher nothwendig den Begriff von Vernunft und Freiheit haben; also selbst ein der Begriffe fähiges Wesen, eine Intelligenz, und, da eben erwiesener Maassen dies nicht möglich ist, ohne Freiheit, auch ein freies, also überhaupt ein vernünftiges Wesen, seyn, und als solches gesetzt warden. $(\mathrm{GAI} / 3,345)^{6}$

En este pasaje, Fichte muestra que la actividad de la exhortación presupone la interacción entre dos seres racionales: el sujeto que recibe la exhortación y el sujeto que la efectúa. El objetivo final de la exhortación es demandar en el otro la realización de una acción libre y autodeterminada. Por ese motivo, explica Fichte, el ser racional que recibe una exhortación no puede considerarse nunca como un ser forzado a actuar de una determinada manera. La exhortación tiene el carácter de una demanda que el otro puede satisfacer o no. En este aspecto, la influencia que la exhortación ejerce sobre el ser racional no puede compararse con una determinación causal que un objeto material puede producir sobre otro de la misma índole. La relación entre dos seres racionales a través de la exhortación no puede identificarse con la relación causa-efecto entre dos cuerpos físicos. Estos cuerpos pueden actuar unos sobre otros, sin necesidad de comprender su propia actividad. La exhortación, en cambio, requiere la comprensión del significado de ciertos conceptos, que se encuentran expresados en la exigencia dirigida al ser racional.

\footnotetext{
6 "La exhortación es la materia del operar, y una actividad causal libre del ser racional a la que invita es su fin final. El ser racional en modo alguno debe ser determinado y forzado a actuar mediante la exhortación, como sucede con lo causado por la causa en el concepto de causalidad; sino que debe autodeterminarse a la acción sólo en virtud de aquella exhortación. Pero si debe suceder esto, ante todo debe comprender y concebir la exhortación, y cuenta con su conocimiento previo. La causa de la exhortación, puesta fuera del sujeto, tiene que suponer al menos la posibilidad de que el último pueda comprenderla y concebirla, pues de otra manera su exhortación no tiene fin alguno. La finalidad de la misma está condicionada por el entendimiento y por la libertad del ser al que ella se dirige. De ahí que esta causa haya de tener necesariamente el concepto de razón y libertad; por tanto, él mismo tiene que ser capaz de conceptos, una inteligencia, $y$, en la medida en que ha quedado demostrado que esto no es posible sin libertad, también un ser libre, por consiguiente, un ser racional, y tiene que ser puesto como tal".
} vol.08, no. 03, Rio de Janeiro, 2015. pp. 1481-1508 
La exhortación, además, no demanda cualquier tipo de acción, sino una acción libre y autodeterminada. La exhortación no representa una simple influencia sobre un sujeto, sino una influencia que no suprime su libertad o su racionalidad. Para que la exhortación pueda resultar efectiva y cumplir con su finalidad, debe dirigirse a un ser racional, es decir, a un ser que puede comprender el significado de esa exhortación. Ahora bien, para comprender el significado de la exhortación, el ser racional que recibe esa exhortación debe poseer los conceptos de razón y libertad. Pero esta comprensión del significado de la exhortación debe ser recíproca: no sólo debe comprenderla quien la recibe, sino también quien la efectúa. Por ese motivo, Fichte afirma que la "causa" de la exhortación (es decir, quien dirige a otro la exhortación de actuar libremente) también debe poseer necesariamente los conceptos de razón y libertad. Quien produce una exhortación no puede ser un cuerpo material e inerte, sino más bien "una inteligencia” (eine Intelligenz). En otras palabras, quien es capaz de dirigir a otro una exhortación debe también comprenderse como un ser racional.

Si existe entonces una causa racional de la exhortación que yo mismo recibo, tengo que admitir que esa causa posee algún "concepto del fin" (Begriff vom Zwecke) de su propia actividad. Según Fichte, aquél que influye sobre nosotros tiene como fin que nosotros lo podamos reconocer como tal. La exhortación no tiene como fin la determinación del otro por la fuerza. La exhortación tiene que comprenderse, en realidad, como una acción que presupone el uso libre de la razón por parte del "objeto" al cual se dirige. Por ese motivo, Fichte sostiene que la influencia de un ser racional sobre otro tiene que entenderse como una acción que propone un conocimiento (GA I/3, 346). En tanto propone un tipo particular de conocimiento, Fichte sostiene que la exhortación a la espontaneidad libre puede también denominarse "educación" (Erziehung). Todos los individuos tienen que ser educados (es decir, recibir una exhortación) para llegar a convertirse en seres racionales. El carácter propio de la humanidad consiste precisamente en este aspecto pedagógico de la exhortación, como una acción recíproca entre seres libres mediante conceptos. La exhortación puede comprenderse entonces como un dar y recibir conocimientos (GAI/3, 347-348).

Ahora bien, este conocimiento exigido por la exhortación no es el conocimiento de un objeto cualquiera de la naturaleza, sino el conocimiento de otro ser racional fuera de mí. La argumentación de Fichte en este pasaje de su deducción puede resumirse del siguiente modo. En tanto me pongo a mí mismo como un ser racional, me pongo necesariamente frente a un mundo. Ese mundo contiene "objetos irracionales" (vernunftlose Objecte) y "seres racionales" (vernünftige Wesen) semejantes a mí (GA I/3, 348). La realidad de ese mundo es efectivamente una condición de mi propia autoconciencia, porque no puedo representarme a mí mismo como un individuo, sin poner algo externo a lo cual atribuyo la misma realidad que yo tengo. Pero ese mundo externo como condición de mi autoconciencia no se funda en la realidad de los objetos irracionales, sino en la realidad de los seres racionales fuera de mí. Según Fichte, es contradictorio para un ser racional presuponer una realidad que debe 
existir, aún cuando se hace abstracción de toda razón. Aquél que pregunta por el fundamento de la realidad del mundo externo es un ser racional, que dispone de la facultad de la razón, que pregunta impulsado por un fundamento racional, y que pretende obtener siempre una respuesta racional a su pregunta. En ningún momento, quien formula la pregunta por la realidad del mundo externo puede hacer abstracción del uso de la razón (GA I/3, 348). Por ese motivo, quien reflexiona sobre las condiciones de su propia autoconciencia individual debe admitir la existencia de un mundo externo, aunque su reconocimiento de un mundo exterior a él no esté basado en un conocimiento directo de los objetos de la naturaleza, sino en una exhortación a reconocer a otros seres racionales fuera de él.

De este modo, Fichte anticipa también el concepto de "reconocimiento" (Anerkennung), que cumple una función decisiva en la tercera etapa de su argumentación. A través de su exhortación, el ser racional que se encuentra fuera de mí exige que yo lo reconozca como tal. Según Fichte, cada uno de nosotros puede descubrir de manera reflexiva esta exigencia de reconocimiento como una condición de la propia autoconciencia individual. De este modo, Fichte demuestra que un ser racional no puede ser autoconciente, a menos que pueda intuir una exhortación a actuar libremente. Si él admite recibir esta exhortación, debe admitir igualmente que hay un ser fuera de él que es la causa determinante de esa exhortación. Ese ser fuera de él debe reconocerse necesariamente como otro ser racional.

Finalmente, Fichte completa la deducción trascendental del concepto puro de derecho a través de una tercera etapa de argumentación. En esta tercera etapa, Fichte intenta probar que si un ser racional finito admite otros seres fuera de él, debe pensarse a sí mismo en una relación jurídica con ellos. Hasta el momento, Fichte ha mostrado que el fundamento de la actividad causal del sujeto reside al mismo tiempo dentro de él y fuera de él. Si el sujeto nunca hubiera sido exhortado a la acción, tampoco habría actuado de manera eficiente sobre el mundo sensible. Pero si hubiera sido completamente determinado a actuar por otro, su acción no sería libre ni autodeterminada. Las acciones libres de un ser racional no deben interferir o perturbar las acciones libres del otro. Si reflexionamos sobre la posibilidad de esta actividad libre, no perturbada por la actividad de otros seres racionales, cada uno de nosotros debe asignarse entonces una "esfera" (Sphäre) de libertad. Dentro de esa esfera, cada uno decide libremente realizar determinadas acciones, con total independencia de otro ser racional. Al mismo tiempo, la reflexión sobre la propia actividad obliga a cada uno a atribuir una esfera semejante a otro ser racional, en donde pueda haber una exteriorización de la libertad, que le pertenezca a él de manera exclusiva. Dice Fichte:

Das Subject bestimmt sich als Individuum, und als freies Individuum, durch die Sphäre, in welcher es unter den in ihr gegebenen möglichen Handlungen eine gewählt hat; und setzt ein anderes Individuum ausser sich, sich entgegen, bestimmt durch eine andere Sphäre, in welcher dieses gewählt hat. 
Es setzt sonach beide Sphären zugleich, und nur dadurch ist die geforderte Gegensetzung möglich. (GA I/3,350) ${ }^{7}$

De este modo, el sujeto se determina como individuo libre a través de la esfera en la cual elige entre ciertas acciones posibles, y se contrapone a otro individuo libre fuera de él determinado según otra esfera de elección. A través de una reflexión sobre la condición de su propia actividad libre, el Yo pone simultáneamente dos esferas: la esfera de su propia libertad y la esfera de la libertad del otro. El ser fuera del sujeto puede sobrepasar la esfera a la cual se encuentra limitado, y quitarle al sujeto su propia libertad. De este modo, uno negaría a través de su acción la libertad del otro. Para que la libertad del Yo sea preservada, el ser racional fuera de él sólo debe dirigirle una exhortación a actuar con libertad y autodeterminación (GA I/3, 350-351). En otras palabras, mi propia libertad presupone que el otro ha limitado su propia libertad de acción, según el concepto de mi propia libertad. Por ese motivo, Fichte afirma que el ser racional que limita su propia actividad libre y decide formular una exhortación, realiza una acción cuya finalidad consiste en preservar la libertad de otro. El ser racional fuera de mí, que me ha exhortado a un actuar libre, ha limitado el uso de su libertad según el concepto de mi propia libertad. Su principal finalidad en esa exhortación ha sido garantizar el ejercicio de mi propia libertad y la conservación de mi propia esfera de acción (GAI/3, 350-351).

En la reflexión sobre mi propia actividad como un ser racional y libre, descubro entonces una "acción recíproca" (Wechselwirkung) con otro ser semejante a mí (GA I/3, 351). Según las propias palabras de Fichte, toda su teoría del derecho está basada en esa reciprocidad entre seres racionales. Yo puedo exigir a otro que me reconozca como un ser racional, en la medida en que yo mismo lo trato como tal. En principio, Fichte explica que esta reciprocidad se aplica esencialmente en una relación intersubjetiva. La exigencia de reconocimiento no la dirige un sujeto a la conciencia moral del otro, así como tampoco al Estado. Yo no exijo que el otro me reconozca meramente ante su propia conciencia (porque eso corresponde a la moral), así como tampoco exijo que el otro me reconozca frente a los demás (porque eso corresponde al Estado). El reconocimiento exigido corresponde, en primer lugar, a una instancia diferente constituida únicamente por la unidad sintética entre mi conciencia y la suya (GAI/3,352).

Fichte advierte también que no puedo limitar esta relación de reciprocidad intersubjetiva a un caso particular o a un conjunto de casos particulares, sino a todos los casos posibles. Por consiguiente, puede afirmarse que la exigencia de reconocimiento dirigida a los seres racionales es universal y sin excepción. La autoconciencia individual del Yo no es posible, sin esta exigencia de carácter universal. En otras palabras, yo tengo que exigir a todos los seres racionales, en todos los casos posibles, que me reconozcan como un ser racional (GA I/3, 353). De esta manera, Fichte pretende señalar que el reconocimiento del otro como un ser racional no depende de ninguna

\footnotetext{
7 "El sujeto se determina como individuo, y como individuo libre, mediante la esfera en la cual ha elegido una de entre las acciones posibles dadas. Y se contrapone a otro individuo fuera de él determinado por otra esfera en la que éste ha elegido. Por tanto, pone al mismo tiempo dos esferas y sólo por esto es posible la contraposición exigida".
} 
característica particular del individuo (su nacionalidad, su constitución física, su origen étnico, sus creencias religiosas, etc.). Tampoco la exigencia de que el otro me reconozca a mí como un ser racional puede depender de una característica que sólo yo poseo. En realidad, para que el otro me reconozca como un ser racional sólo es necesario que se cumpla una sola condición: que yo también pueda reconocerlo a él como un ser racional. En tanto yo soy capaz de reconocerlo como un ser racional, el otro está obligado a reconocerme también como un ser racional y libre. Este reconocimiento adquiere de este modo una validez general para todo aquél que cumpla esa misma condición. El cumplimiento de esa condición es necesariamente recíproco: el otro cumple la condición de reconocerme como un ser racional y entonces yo estoy obligado también a reconocerlo como tal (GA I/3, 353$354)$.

De acuerdo con la argumentación que ofrece Fichte, la relación entre seres racionales en el contexto de la vida en común se encuentra sometida a una ley que exige coherencia en las acciones y reciprocidad en el reconocimiento. El reconocimiento de un individuo por otro está condicionado por una acción recíproca, en la que ambos conservan su libertad y el uso pleno de su razón. Ninguno tiene que reconocer al otro, si ambos no se reconocen de manera recíproca. Ninguno está obligado a tratar al otro como un ser libre, si no se conceden la libertad de manera recíproca. De esta forma, yo puedo exigir a otro que me reconozca como un ser racional, si yo al mismo tiempo lo trato como tal. Pero, además, yo también tengo que exigir a todos los seres racionales fuera de mí que me reconozcan como un ser racional y libre. Esta exigencia universal de reconocimiento me permite conservar una esfera de libertad para mis acciones, que no puede ser suprimida por un ser racional fuera de mí, y, al mismo tiempo, me obliga a limitar mi propia actividad libre, para no dañar la esfera de libertad de otro ser racional. Dice Fichte:

Ich setze mich als Individuum im Gegensatze mit einem anderen bestimmten Individuum, indem ich mir eine Sphäre für meine Freiheit zuschreibe, von welcher ich den anderen, und dem anderen eine zuschreibe, von welcher ich mich ausschließe - es versteht sich lediglich im Denken eines Factums, und zufolge dieses Factums. Ich habe mich also frei gesetzt; neben ihm, und unbeschadet der Möglichkeit seiner Freiheit. Durch dieses Setzen meiner Freiheit habe ich mich bestimmt; das Freiseyn macht meinen wesentlichen Charakter aus. $(\mathrm{GA} \mathrm{I} / 3,357)^{8}$

Según Fichte, yo me pienso como individuo en oposición a otro individuo determinado, en tanto me atribuyo una esfera de libertad de la cual el otro queda excluido. Al mismo tiempo, atribuyo al otro una esfera de libertad de la cual yo mismo quedo excluido. De este modo, se respetan las libertades individuales, sin negarse de manera absoluta. En definitiva, cada uno debe reconocer al otro como un ser libre, y debe limitar su propia libertad por medio del concepto de la posible libertad del otro. En este sentido, Fichte no sólo utiliza el concepto de

\footnotetext{
8 "Me pongo como individuo en oposición con otro individuo determinado en tanto que me atribuyo a mí una esfera para mi libertad de la que excluyo al otro, y atribuyo al otro una esfera de la que me excluyo - se entiende, únicamente en el pensar de un factum y como consecuencia de este factum. Luego me he puesto como libre, junto a él y sin dañar la posibilidad de su libertad. Me he determinado por este acto de poner mi libertad; el ser libre constituye mi carácter esencial".
} vol.08, nº. 03, Rio de Janeiro, 2015.pp. 1481-1508 
libertad para describir una característica que el individuo ya posee en el momento presente, sino también como una exigencia que debe cumplir en el futuro. Es decir, la libertad exigida para mis acciones tiene un significado normativo, en tanto me exige actuar de manera libre (aún cuando yo no sea libre en el presente). Yo puedo considerarme como un ser libre, explica Fichte, si soy capaz de realizar el concepto de fin proyectado para mis propias acciones. Ahora bien, el fin de mi actividad siempre es proyectado hacia el futuro. Por ese motivo, la libertad de las acciones individuales siempre es puesta en el futuro, aunque no en un momento cronológico determinado, sino "en todo el futuro del individuo" (für alle Zukunft des Individuums). Esta exigencia de libertad no sólo tiene validez para mí, sino también para todo ser racional contrapuesto a mí. Como ya se ha visto, mi esfera de libertad sólo es posible, en la medida en que el otro permanece dentro de la suya. De la misma manera que estoy sometido a la exigencia de realizar mi libertad para todo el futuro, tengo que exigir también al otro su autolimitación para todo el tiempo futuro (GAI/3,357).

En otras palabras, yo exijo al otro una coherencia en sus acciones: que no sólo actúe de manera racional algunas veces, sino siempre. Yo no exijo al otro que me reconozca como un ser racional en determinados momentos (hoy, mañana, la semana próxima, etc.), sino en todo futuro posible. Esta exigencia de coherencia en las acciones también es recíproca: no sólo es válida para el otro, sino también para mí. El otro sólo puede reconocerme como un ser racional, bajo la condición de que yo también lo reconozca como tal. Por lo tanto, yo también debo cumplir la exigencia de actuar con coherencia en todo futuro posible. De acuerdo con esa exigencia, tengo que reconocer al otro como un ser racional y libre, "en todos los casos" (in allen Fällen).

La exigencia de un reconocimiento recíproco entre seres racionales puede entenderse entonces como una exigencia con validez universal. En todos los casos posibles, tengo que limitar mi propia libertad, según el concepto de la libertad del otro. Según Fichte, esta relación entre seres racionales tiene que pensarse necesariamente como una "relación jurídica" (Rechtsverhältniß):

Das deducirte Verhältniß zwischen vernünftigen Wesen, daß jedes seine Freiheit durch den Begriff der Möglichkeit der Freiheit des anderen beschränke, unter der Bedingung, daß das erstere die seinige gleichfalls durch die des anderen beschränke, heißt das Rechtsverhältniß; und die jetzt aufgestellte Formel ist der Rechtssatz. Dieses Verhältniß ist aus dem Begriffe des Individuums deducirt. Es ist sonach erwiesen, was zu erweisen war. Ferner ist vorher der Begriff des Individuums erwiesen worden, als Bedingung des Selbstbewußtseyns; mithin ist der Begriff des Rechtes selbst Bedingung des Selbstbewußtseyns. Folglich ist dieser Begriff gehörig a priori, d.h. aus der reinen Form der Vernunft, aus dem Ich, deduciret. (GA I/3, $358)^{9}$

\footnotetext{
9 "La relación entre seres racionales deducida, a saber, que cada uno limite su libertad por el concepto de la posibilidad de la libertad del otro, bajo la condición de que éste limite igualmente la suya por la del otro, se llama relación jurídica, y la fórmula ahora establecida es el principio de derecho. Esta relación está deducida desde el concepto de individuo. Se ha demostrado así lo que había que demostrar. Además, antes se ha demostrado el concepto de individuo como condición de la autoconciencia; por vol.08, nº.03, Rio de Janeiro, 2015.pp. 1481-1508 1495
} 
Según Fichte, entonces, puede denominarse relación jurídica precisamente a la relación recíproca entre seres racionales, donde cada uno limita su libertad en favor de la posible libertad del otro. La exigencia de limitar mi propia libertad y no interferir en la libertad ajena puede considerarse, además, el "principio del derecho" (Rechtssatz). Fichte deduce ese principio a partir de la propia actividad autoconsciente del individuo como ser racional. En este sentido, Fichte intenta demostrar que el mencionado concepto de derecho está presupuesto en la actividad del individuo como condición de su autoconciencia. Ningún individuo puede afirmarse como un ser autoconciente, sin reconocer al mismo tiempo la validez universal y necesaria del concepto de derecho. A su vez, Fichte ha intentado deducir esa autoconciencia a partir de la mera actividad del sujeto individual. La actividad realizada por el individuo y dirigida hacia el mundo sensible es una condición de la autoconciencia. Esa actividad está sometida necesariamente al principio del derecho y constituye la condición de la autoconciencia de un ser racional.

\section{LA VALIDEZ HIPOTÉTICA DEL CONCEPTO DEL DERECHO}

Como se ha visto en la sección anterior, Fichte muestra que la validez a priori del concepto puro derecho puede ser deducida a partir de una reflexión sobe el mero uso de la razón por parte de un individuo. Según Fichte, el concepto puro de derecho se funda simplemente en la "esencia de la razón" (im Wesen der Vernunft) y no en la experiencia, en la instrucción o en las reglamentaciones vigentes entre los hombres (GA I/3, 358). Con estas palabras, Fichte señala el carácter estrictamente trascendental y normativo de su deducción del concepto de derecho. A través de su procedimiento deductivo, Fichte no pretende describir una comunidad humana real, tal como podía existir efectivamente en su época, así como tampoco intenta pronosticar la necesaria instauración de esa comunidad en alguna etapa posterior del desarrollo histórico de la humanidad. Según Fichte, la realización de una comunidad de seres racionales y libres, según el concepto de derecho natural deducido por él, siempre dependerá de una decisión libre y contingente de los hombres. En otros términos, la deducción fichteana del concepto de derecho muestra cómo debería ser una comunidad de seres racionales, pero no garantiza que esa comunidad sea efectivamente instaurada en algún momento de la historia (GA I/3 320).

El principio fichteano del derecho se fundamenta así en una exigencia normativa de la razón, y no en un dato empírico, adquirido a partir de la experiencia, descubierto en una investigación sobre el pasado histórico o impuesto arbitrariamente por los hombres en el contexto de una sociedad determinada. Fichte elimina todas esas condiciones empíricas del derecho, adoptando como único punto de partida de su deducción trascendental la pura actividad de un sujeto individual y su mera pretensión de racionalidad. Si alguien pretende ser reconocido

consiguiente, el concepto de derecho mismo es condición de la autoconciencia. Por tanto, este concepto es deducido a priori desde el Yo, como es debido, esto es, a partir de la forma pura de la razón”. 
como un ser racional, entonces debe admitir que es un individuo autoconciente y libre, que debe relacionarse con otros individuos, a los cuales también debe reconocer como seres racionales, autoconcientes y libres. Como se ha visto, el concepto a priori del derecho sólo exige una relación de reciprocidad entre estos seres racionales. Si alguien se piensa a sí mismo como un ser racional, entonces también debe admitir que posee el concepto de derecho y está dispuesto a actuar según ese concepto en todas sus posibles relaciones con otro ser racional. Con su deducción del concepto puro de derecho, Fichte no pretende ofrecer una descripción de la legalidad jurídica vigente en una sociedad humana real, situada en un período determinado de la historia. El objetivo de Fichte consiste más bien en incorporar una teoría normativa del derecho a su sistema total de la Doctrina de la Ciencia. ${ }^{10}$

Ahora bien, Fichte no sólo afirma este carácter normativo de su teoría del derecho, sino que también establece una nítida diferencia entre la normatividad jurídica y la normatividad moral. La normatividad moral es categórica: expresa un mandato que debe obedecerse de manera incondicionada. La normatividad del derecho es sólo hipotética: tiene validez únicamente en la medida en que un hombre desea vivir en comunidad con otros hombres. La validez de las normas jurídicas parece depender siempre de la previa decisión de instituir una comunidad de seres racionales y libres. En este contexto, Fichte afirma que ninguno de nosotros está obligado a vivir en comunidad con otros seres semejantes. La permanencia del individuo en la comunidad quedaría entonces sometida constantemente a su libre decisión. En todo momento, un individuo sería capaz de decidir si quiere mantener ese vínculo con la comunidad o si por el contrario desea interrumpirlo. Por su parte, el concepto de derecho sólo establece que, cuando alguien no desea limitar sus acciones en beneficio de la libertad de los demás, está obligado a abandonar la sociedad humana (GA I/3 320-322).

Por ese motivo, Fichte afirma también que el concepto de derecho es un concepto "técnico-práctico" (technisch-praktisch). En este punto, Fichte parece recurrir a la distinción entre los imperativos categóricos y los imperativos hipotéticos que Kant establece en su Kritik der praktischen Vernunft (1788). Según Kant, un imperativo categórico determina absolutamente la voluntad (como si no hubiese más fundamento de determinación de la voluntad que la mera razón). En cambio, un imperativo hipotético sólo determina la voluntad

\footnotetext{
${ }^{10}$ Este carácter normativo de la deducción fichtena del derecho natural ha sido también destacado por Michael Baur en un artículo publicado hace ya algunos años. Según Baur, Fichte establece una estrecha conexión entre una epistemología dogmática o precrítica y un pensamiento político autoritario. Según Fichte, la tarea de una filosofía crítica consiste en ofrecer una explicación de nuestro conocimiento de objetos, sin recurrir al presupuesto dogmático de una cosa en sí fuera del sujeto cognoscente. Este mismo enfoque debe ser trasladado al ámbito de la razón práctica. Quien pretenda interpretar adecuadamente el espíritu de la filosofía crítica debe ser capaz de ofrecer una explicación de las normas u obligaciones a las cuales estamos comprometidos en el ámbito de la praxis, sin referirse a ninguna premisa dogmática previamente establecida. Fichte asume así la tarea de proporcionar una explicación de la normatividad práctica (practical normativity) sin apelar a ningún presupuesto ontológico o teleológico previamente aceptado. En otras palabras, el objetivo de Fichte consiste en ofrecer una explicación de nuestras exigencias normativas en el ámbito de la actividad práctica, sin recurrir a ninguna noción previa de Naturaleza, Bien, Finalidad, etc., que pueda establecerse de manera independiente a nuestra propia voluntad autolegisladora (self-legislative willing). Como comenta Baur, Fichte pensaba que, para completar el proyecto emancipatorio de la Revolución Francesa, era necesario antes completar el proyecto de la Revolución Copernicana, superando el dogmatismo residual de todo naturalismo y de toda teleología (Baur, 2006:11-15).
} vol.08, nº. 03, Rio de Janeiro, 2015.pp. 1481-1508 
bajo una cierta condición (por ejemplo, la condición de satisfacer un deseo previamente establecido). En este sentido, Kant sostiene que los imperativos hipotéticos para la acción pueden considerarse sólo como preceptos de habilidad (KpV A 37). Fichte parece comprender el concepto de derecho precisamente como un imperativo hipotético o técnico-práctico, en tanto se encuentra siempre condicionado por el deseo del hombre de vivir en sociedad. Por ese motivo, Fichte afirma también que el concepto de derecho no debe identificarse con el imperativo categórico de la moralidad. En definitiva, Fichte nos dice que su teoría del derecho no debe confundirse con su teoría sobre la moralidad. Aunque su doctrina del derecho natural no es incompatible con su ética, la primera puede comprenderse de manera totalmente autónoma (GA I/3 320-321). ${ }^{11}$

De este modo, la exposición sistemática de la Doctrina de la Ciencia durante el período de Jena se ocuparía de dos ámbitos específicos de la praxis humana claramente delimitados: el derecho y la moral. Para cada uno de esos ámbitos, Fichte ofrece una correspondiente deducción de sus principios y de su posibilidad de aplicación. En efecto, el derecho constituye un ámbito específico de aplicación de los principios normativos de la razón (a saber, el ámbito de las relaciones interpersonales en el mundo sensible). Por ese motivo, Fichte señala que el principio del derecho no puede identificarse con el principio de la moral. El derecho y la moral son dos ámbitos diferentes de la racionalidad práctica. En primer lugar, como ya se ha dicho, el principio de la moral se expresa bajo la forma de un imperativo categórico. La ley moral ordena de manera categórica e incondicionada a todos los individuos el cumplimiento del deber (GA I/3, 359). En cambio, la ley jurídica sólo exige el cumplimiento del principio de derecho, bajo la condición de que sea preservada la vida en comunidad. En segundo lugar, la ley moral sólo parece tener una validez intrasubjetiva: únicamente se refiere a la relación del sujeto consigo mismo en la determinación de su voluntad. Aunque, desde luego, el sujeto determina su voluntad para la acción, la moral no contempla los posibles efectos de esa acción en el mundo sensible. El concepto de derecho, en cambio, tiene una validez intersubjetiva, en tanto se refiere específicamente a la interacción entre dos o más sujetos. Por ese motivo, el principio de derecho necesita considerar las acciones tal como se manifiestan en el mundo externo. Según Fichte, aquello que no produce ningún efecto en el mundo externo, sino que permanece en el interior de la conciencia, sólo puede ser juzgado por el "tribunal" (Richterstuhl) de la moral (GA I/3, 360). El problema del derecho sólo aparece cuando las acciones de un ser racional pueden tener consecuencias o efectos sobre otro. El concepto de derecho presupone así una interacción real entre dos seres racionales en el marco de una vida comunitaria.

\footnotetext{
${ }^{11}$ En su GNR de 1796/97, Fichte parece considerar efectivamente que el derecho natural es susceptible de una fundamentación independiente de la deducción de la ley moral. No obstante, en su Beitrag zur Berichtigung der Urtheile des Publicums über die französische Revolution de 1793, Fichte parece comprender esta relación entre moralidad y derecho de una manera totalmente distinta. Tal como señala Violetta Weibel, Fichte sostiene en este escrito de 1793 que el derecho natural no es susceptible de una deducción autónoma y sólo puede ser derivado a partir de la ley moral. (Waibel, 2006: 45-58). Alain Renaut observa esta misma modificación en el pensamiento jurídico de Fichte (Renaut, 1986: 230-237).
} 
A pesar de todo, en el contexto de su teoría del derecho natural, Fichte también hace algunas afirmaciones que sugieren la posibilidad de adjudicar al principio del derecho una validez categórica. Estas afirmaciones presuponen una distinción entre juicios categóricos y juicios problemáticos, que Fichte parece haber extraido de la Kritik der reinen Vernunft de Kant. Es preciso recordar aquí que, de acuerdo con la definición kantiana, un juicio problemático es aquella clase de juicio donde se considera la afirmación o la negación como meramente posible o arbitraria (KrV A74-B100). Según Kant, la proposición problemática es aquella que expresa solamente la posibilidad lógica de un hecho. Frente a este tipo de proposiciones, cada uno puede tomar la libre decisión de concederle alguna validez o de negársela. Por consiguiente, este tipo de proposiciones admiten siempre la posibilidad de una aceptación arbitraria por parte del entendimiento ( $\mathrm{KrV}$ A75-B101). Algo diferente ocurre ciertamente en el juicio categórico, que afirma una relación necesaria entre el sujeto y el predicado $(\mathrm{KrV}$ A73-B98). En su GNR de 1796/97, Fichte adopta esta distinción kantiana y la aplica en su reflexión sobre la validez del principio de derecho. Desafortunadamente, su posición sobre este tema tampoco está exenta de ambigüedades, aunque resulta desde luego muy significativa. Inicialmente, Fichte sitúa los juicios categóricos y los juicios problemáticos en dos planos bien diferenciados, pero luego establece una claúsula que permite identificarlos. En efecto, Fichte afirma que todo juicio problemático puede transformarse en categórico, cuando al primero se añade una condición que se cumple de manera efectiva. El principio del derecho admitiría precisamente este proceso de transformación. El contenido de este principio se afirma primero como posible en el contexto de un juicio problemático y, con el cumplimiento de una determinada condición, se transforma en categórico. En este caso, si se admite la condición, entonces necesariamente hay que admitir también lo condicionado por ella. De este modo, la relación de reconocimiento mutuo entre dos seres racionales y libres, que se afirma en primer lugar como meramente posible bajo la forma de un juicio problemático, se convierte luego en el contenido de un juicio categórico, una vez que se cumple efectivamente una cierta condición. En el caso del principio del derecho, explica Fichte, la condición era que yo tenía que reconocer al otro como un ser racional (esto es, que yo tenía que tratarlo como tal). Debo hacer esto necesariamente, tan cierto como que me opongo a él como un individuo racional y en la medida en que actúo racionalmente (es decir, en la medida en que actúo de manera consecuente con mis conocimientos). A su vez, tan pronto como yo lo reconozco, él esta obligado necesariamente a reconocerme a mí como un ser libre de forma categórica y con una validez en común. Esta obligación se desprende necesariamente de su primera expresión problemática y se deriva como una consecuencia estrictamente racional a partir de ella (GA I/3 353-354). Se ha producido aquí, explica Fichte, una unificación de opuestos en una unidad. Bajo el presupuesto actual, ese punto de unificación se encuentra en mi conciencia y la unificación misma está condicionada por el hecho de que yo soy capaz de autoconciencia. El otro, por su parte, cumple la condición bajo la cual yo lo reconozco y me impone a mí esa misma condición. Por mi 
parte, yo cumplo también la condición y lo obligo por medio de ello a seguir las consecuencias de la condición que él mismo estableció previamente: a saber, reconocerme de manera categórica (GA I/3 353-354). Con estas observaciones, Fichte parece también admitir que es posible atribuir al concepto de derecho una validez categórica.

\section{INDIVIDUO Y COMUNIDAD}

Cuando se analiza convenientemente la fundamentación fichteana del derecho natural, resulta legítimo preguntarse por la verdadera autonomía del derecho dentro del sistema filosófico de Fichte, especialmente con respecto a su doctrina ética. A primera vista, Fichte establece un criterio de distinción muy claro entre ambas disciplinas. A diferencia del principio de la ética, que posee una validez categórica, el principio fichteano del derecho tendría sólo una validez hipotética. Es decir, el derecho es válido únicamente para una conciencia individual que desea permanecer dentro del contexto de una comunidad. Sin embargo, ies posible para Fichte admitir otro modo de existencia individual? En efecto, Fichte parece establecer una esencial relación de dependencia entre la existencia del individuo y la existencia de la comunidad, en diversos pasajes de su GNR de 1796/97. En un pasaje de su deducción de la aplicabilidad del concepto de derecho, por ejemplo, Fichte intercala una serie de extensos corolarios, donde establece una comparación entre la especie animal y la especie humana. Los comentarios de Fichte en este pasaje de su obra insisten sobre el tópico de la esencia incompleta del hombre y de su necesaria relación con el entorno social. Estas observaciones de carácter antropológico nos obligan a concebir al hombre básicamente como un ser frágil e indeterminado, que no sólo necesita de su entorno comunitario para conservar su vida biológica, sino también para alcanzar un cierto nivel de determinación como ser racional.

De acuerdo con la explicación de Fichte, puede advertirse una notable diferencia entre un animal y un hombre. Cualquier animal se mueve hacia el pecho materno, desde las primeras horas de su nacimiento, guiado únicamente por el instinto. Su movimiento presupone ya ciertas leyes naturales, mecánicas e instintivas, que garantizan su supervivencia. En cambio, el hombre carece de este auxilio del instinto natural y necesita entonces de la libre colaboración de otros hombres para no morir. Además, el hombre nace desnudo, mientras que el animal nace cubierto por un pelaje que lo protege de las inclemencias del tiempo. El animal nace con ciertas capacidades innatas para moverse y desplazarse en el espacio. El hombre, por desgracia, no posee nada similar. No hay indicios que permitan inferir que el hombre se encuentra particularmente determinado a caminar erguido o en cuatro patas. Incluso las capacidades humanas de la percepción o del habla no parecen estar provistas meramente por la naturaleza, sino que obedecen a un posterior proceso de aprendizaje. La boca del rostro humano parece estar destinada por naturaleza a cumplir meramente una función nutritiva. Sólo mediante un proceso de educación, esa 
misma boca se convierte en un órgano de comunicación y en un medio de expresión de sentimientos sociales. Según Fichte, todos estos hechos permiten ilustrar una originaria condición de "desamparo" (Hülflosigkeit) en el hombre, como si la naturaleza hubiese decidido dejar la especie humana confiada a sí misma. El hombre sólo puede adquirir una determinada figura (e incluso puede conservar su propia especie), a través de la educación y del uso de la razón (GA I/3, 380-383).

Conclusiones similares pueden extraerse, cuando se analizan algunos pasajes de la GNR de 1796/97, donde Fichte nos habla de una relación intersubjetiva entre los miembros de una comunidad como condición de posibilidad de la autoconciencia individual. ${ }^{12}$ Como ha podido observarse en la primera sección del presente artículo, Fichte sugiere la misma relación de dependencia entre el individuo y la comunidad que lo rodea, cuando utiliza los conceptos de "exhortación" (Aufforderung) y de "reconocimiento" (Anerkennung). ${ }^{13}$ En ese contexto deductivo, Fichte sostiene que todo sujeto que reflexiona sobre las condiciones de su propia autoconciencia individual debe admitir la existencia de un mundo externo. Sin embargo, este reconocimiento de un mundo exterior a él no está basado en un conocimiento directo de los objetos de la naturaleza, sino en una exhortación a reconocer a otros seres racionales fuera de él. A través de esa exhortación, un ser racional que se encuentra fuera de él le exige ser reconocido como tal. Según Fichte, cada uno de nosotros puede descubrir de manera reflexiva esta exigencia de reconocimiento como una condición de su propia autoconciencia individual. De este modo, Fichte demuestra que un ser racional no puede ser autoconciente, a menos que pueda intuir en sí mismo una exhortación a actuar libremente. Si él admite recibir esta exhortación, debe admitir igualmente que hay un ser fuera de él que es la causa determinante de esa exhortación. Ese ser fuera de él debe reconocerse necesariamente como otro ser racional, porque la exhortación nunca implica el uso de la fuerza bruta, sino sólo la comunicación de un concepto. Para que la libertad del Yo sea preservada, el ser racional fuera de él sólo debe dirigirle una "exhortación" a actuar con libertad y autodeterminación (GA I/3 350-351).

Según Fichte, entonces, no puedo pensarme a mí mismo (es decir, no puedo tener ninguna autoconciencia) como un ser racional, sin admitir una relación de reciprocidad necesaria con otro ser racional. Por ese motivo, Fichte afirma que el concepto de un individuo (como ser racional finito) es un "concepto recíproco" (Wechselbegriff). El concepto de mi propio Yo como individuo no puede ser únicamente un concepto de mi propio pensamiento, sino un concepto también compartido por el pensamiento de otro. El concepto de mi propia

\footnotetext{
${ }^{12}$ En las últimas décadas, el problema de la intersubjetividad en la filosofia de Fichte ha sido ampliamente analizado en el contexto de la crítica especializada (Honneth, 2001: 63-80; Riobó González, 1988; Siemek, 1997: 241-252; Siemek, 2003: 57-75; Richli, 1997: 351-363; Düsing, 1997: 113-132; Ivaldo, 2003: 59-73; Wood: 2006: 62-79; Senigaglia, 2007: 163-177; Zöller 2007: 125145).

${ }^{13}$ Sobre el concepto de reconocimiento en la filosofia de Fichte y en el Idealismo Alemán también existe una abundante bibliografía crítica que ha crecido mucho en los últimos años (Siep, 1978; Honneth, 1996; Williams, 2006: 26-44; Nowak-Juchacz, 2003: 7584; Binkelman, 2007: 122 ss; Mather, 2003: 85-103). Con el concepto de exhortación ocurre algo similar (Honneth, 2001: 74-77; Siemek, 2003: 60-62).
} 
individualidad nunca depende únicamente de mi propio reconocimiento, sino también del reconocimiento de otro. En este sentido, cuando reflexiono sobre el concepto de mi propia individualidad, estoy también obligado a reconocer que es un concepto común, compartido por mi propia conciencia y por la conciencia del otro. Por ese motivo, dice Fichte, estamos autorizados a hablar de una "comunidad de la conciencia" (Gemeinschaft des Bewusstseyns). De esta manera, Fichte intenta demostrar que la autoconciencia individual presupone necesariamente el concepto de una comunidad. Cuando me pienso a mí mismo como un individuo, me pienso necesariamente en el contexto de una comunidad con otros seres racionales semejantes a mí (GA I/3 354-356). Por ese motivo, además, Fichte rechaza una concepción individualista del hombre. El concepto de hombre no es en absoluto el concepto de un individuo, sino el concepto de un género. Es decir, un individuo llega a convertirse verdaderamente en un hombre en el contexto de las relaciones intersubjetivas que mantiene con otros individuos de su mismo género. En este proceso de integración a una comunidad humana, la exhortación cumple una función imprescindible. Según las palabras del propio Fichte, la exhortación a la libre autodeterminación es lo que se denomina "educación" (Erziehung) y todos los individuos tienen que ser educados para llegar a ser hombres (GAI/3, 347).

Este rechazo de una concepción individualista del hombre no parece tampoco un aspecto fortuito o accidental, sino más bien una parte esencial dentro del proyecto filosófico de Fichte. En la más reciente literatura especializada, la formulación de una verdadera teoría de la intersubjetividad aparece con mucha frecuencia como una importante contribución de Fichte al movimiento del Idealismo Alemán y a toda la historia de la filosofía (Honneth, 2001: 63-80; Riobó González, 1988; Siemek, 1997: 241-252; Siemek, 2003: 57-75; Düsing, 1997: 113-132; Ivaldo, 2003: 59-73; Senigaglia, 2007: 163-177; Zöller 2007: 125-145). En efecto, el interés por el problema de la intersubjetividad aparece de forma muy temprana en la obra de Fichte. Antes de alcanzar una explícita formulación de su teoría del derecho, Fichte ya había afirmado efectivamente esta misma intersubjetividad constitutiva del Yo en algunos escritos muy significativos de su período de Jena (1794-1799). Aunque todavía de un modo excesivamente formal y abstracto, Fichte se refiere sin dudas a esta intersubjetividad en su Grundlage der gesammten Wissenschaftslehre de 1794/95, cuando establece una necesaria relación entre un Yo (Ich) y un Tú (Du) como condición de la posibilidad de la autoconciencia. El mencionado problema de la intersubjetividad aparece allí en el horizonte de las posibles relaciones entre el Yo y el No-Yo. En un pasaje muy significativo sobre este tema, Fichte afirma: "No hay Tú, sin Yo; no hay Yo, sin Tú" (Kein Du, kein Ich; kein Ich, kein $\mathrm{Du}$ ). En este contexto, Fichte se refiere a la imposibilidad de encontrar un criterio meramente lógico o especulativo para establecer una distinción entre Yo y No-Yo. Ambos conceptos parecen inextricablemente unidos. El Yo es puramente lo opuesto del No-Yo y nada más que eso. A la inversa, el No-Yo es puramente lo opuesto del Yo. El sujeto es aquello que no es objeto, y no tiene más predicado que ése. Por su parte, el objeto es 
aquello que no es sujeto, sin más predicado que ése (GA I/2, 337). Sin dudas, el aspecto más significativo de este pasaje se encuentra en la mencionada identificación entre el No-Yo y una posible segunda persona (con la que presumiblemente podría establecerse una relación dialógica y no meramente instrumental). De este modo, Fichte parece anticipar su posterior concepto de intersubjetividad y asegurar las bases teóricas para afirmar luego la dependencia intersubjetiva entre seres racionales.

En Einige Vorlesungen über die Bestimmung des Gelehrten de 1794/95, Fichte también se refiere a la dimensión intersubjetiva de la conciencia humana, aunque en esta oportunidad bajo la forma de un "impulso social" (gesellschaftliche Trieb) que permite el necesario reconocimiento entre los seres racionales. En este impulso a la socialización, el Yo trascendental fichteano contiene en sí mismo una relación previa con un Nosotros. De esta manera, Fichte admite aquí que tampoco la estructura interna de la subjetividad puede ser comprendida sin su necesaria dimensión de intersubjetividad. En otras palabras, la conciencia individual no puede puede concebirse sin un vínculo esencial de socialización, que tiene como resultado la interacción de los seres racionales entre sí. Según la perspectiva de Fichte, el hombre se encuentra determinado originariamente para esa vida en sociedad. Entre las facultades esenciales del hombre, explica Fichte, debemos considerar necesariamente su "sociabilidad" (Gesellschaftlichkeit). Esta sociabilidad puede representarse como un impulso que pertenece a la estructura más íntima del ser humano. En tanto que mero impulso, queda siempre subordinado a la ley moral (que Fichte define en este contexto como la ley de la permanente coincidencia del Yo consigo mismo). El impulso a la socialización surge de nosotros mismos, buscando fuera de nosotros otro ser racional semejante para establecer con él una comunidad. El impulso social de un ser racional no pretende en este caso someter a su objeto a una relación de subordinación, como sucede en el mundo meramente físico o corporal, sino que aspira a establecer una relación de coordinación con un ser también dotado de razón (GA I/3, 38-39). El hombre, argumenta Fichte, necesita utilizar cosas carentes de razón como medios útiles para alcanzar sus fines. Pero no puede utilizar a otros seres racionales con ese mismo propósito. No puede actuar sobre los seres racionales como si se tratara de animales o de materia muerta, de manera que pudiera llevar a cabo mediante ellos sus propios fines, sin haber tenido en cuenta su condición de seres libres. Un hombre no puede convertir a otro en feliz, sabio o virtuoso, actuando contra su propia voluntad (GA I/3 39-40).

La misma relación de dependencia entre el Yo y su entorno social ya había aparecido también en el contexto de la teoría fichteana del lenguaje. En su escrito titulado Von der Sprachfähigkeit und dem Ursprunge der Sprache de 1795, Fichte concibe al lenguaje como la tarea específica de comunicar a otros el pensamiento por medio de signos audibles o visibles. Desde luego, Fichte no intenta ofrecer allí una explicación empírica, sino una deducción trascendental del lenguaje. Fichte no considera al lenguaje como un producto casual derivado de ciertas convenciones o acuerdos, sino como una herramienta de comunicación que se puede justificar 
necesariamente a partir de la propia estructura de la conciencia humana. Según Fichte, la invención del lenguaje no es un hecho contingente de la historia, sino que ha estado siempre sometida a leyes necesarias de la razón. El lenguaje surge en el contexto de la necesaria relación entre Yo y No-Yo. Este No-Yo fichteano comprende todo aquello que se opone a un sujeto: no sólo el mundo natural, sino también el mundo social humano. En consecuencia, el Yo individual tiene dos maneras alternativas de comportarse frente al No-Yo. Cuando el No-Yo es comprendido como naturaleza, el Yo pretende modificarlo y someterlo completamente. En otras palabras, el sujeto intenta siempre transformar la realidad no-racional para que finalmente concuerde con su ideal práctico, imponiendo por la fuerza las leyes de la razón a la propia naturaleza (GA I/3, 100-101). Pero cuando el sujeto se opone al No-Yo como mundo social y humano tiene que actuar de una manera diferente. En el mundo social, el hombre no se opone a una naturaleza bruta, sino a otros hombres que comparten con él los mismos principios de racionalidad. El reconocimiento de esa racionalidad requiere la posibilidad de una interacción o un intercambio entre sujetos, de la cual resulta una correspondiente modificación de la acción con respecto a fines. No puedo reconocer como racional a un ser que actúa invariablemente o de forma mecánica, independientemente de cualquier interacción que yo pueda tener con él. Según Fichte, sólo puedo reconocer como racional a un ser que modifica sus intenciones, después de entender un acto de comunicación en el que yo expreso mis propias intenciones (GA I/3, 101). Por ese motivo, la posibilidad de reconocer la racionalidad fuera de la esfera subjetiva necesita la invención del lenguaje. Es decir, el reconocimiento mutuo de la racionalidad entre seres de la especie humana depende de la invención de un medio de comunicación adecuado de los pensamientos e intenciones. Sin lenguaje, se vuelve imposible la vida social, porque las acciones de los hombres siempre son susceptibles de una interpretación incorrecta. Los signos del lenguaje están elaborados voluntariamente por el hombre para resolver este problema. Sólo por medio de la utilización de signos lingüísticos puedo comunicar mis propias intenciones y conocer las intenciones de los demás. De esta manera, surge la idea de un lenguaje en el contexto de la interacción social humana (GA I/3, 102-103). De este modo, puede verse que la teoría fichteana del lenguaje se construye también sobre el presupuesto de la dimensión intersubjetiva de la conciencia. Esta teoría no implica únicamente la obvia concepción del lenguaje como un instrumento de interacción entre seres racionales en el marco de la vida social, sino la afirmación de una estructura intersubjetiva que pertenece a priori a la propia conciencia individual. En otras palabras, la deducción trascendental del lenguaje como herramienta de comunicación y de reconocimiento presupone en todo momento la relación intersubjetiva como parte de la estructura de la conciencia del Yo. 


\section{CONCLUSIONES}

Si aceptamos los presupuestos antropológicos de Fichte, resulta ciertamente muy difícl pensar una ética fuera de la comunidad y de su respectivo marco jurídico-normativo (garantizado en última instancia por el poder del Estado). La distinción entre ética y derecho se vuelve entonces un poco difusa. Más allá de su aparente carácter individual o intrasubjetivo, la ética propuesta por Fichte sólo puede realizarse en el mundo sensible de forma colectiva, a través de la permanente interacción entre seres racionales dentro de una comunidad fundada en el derecho y en el poder coercitivo del Estado, durante el transcurso de un progreso histórico virtualmente infinito. Desde luego, este problema adquiere relevancia para una reflexión ética que contemple los efectos y consecuencias de las acciones humanas. Como ocurre con la ética de Kant, la doctrina ética fichteana nunca abandona en sentido estricto la forma de una ética de la intención. Además, Fichte asignó a su doctrina ética un lugar muy específico dentro de su sistema filosófico y tuvo la pretensión de deducirla como una instancia distinta de reflexión de un sujeto autoconsciente. Es decir, la ética corresponde a ese nivel de autoconciencia en que el sujeto reflexiona únicamente sobre los fundamentos de determinación de su propia voluntad, con independencia de los efectos de sus acciones. No obstante, puede decirse que Fichte no se limitó a ofrecer una nueva versión de la ética kantiana, sino que además intentó pensar con mayor exactitud las condiciones de realización de esa ética dentro del mundo sensible. En este sentido, Fichte parece asignarle al derecho la función de garantizar las condiciones para el cumplimiento del ideal práctico de la razón en el espacio de la vida comunitaria. El derecho de Fichte no es independiente de su doctrina ética, sino que más bien parece estar subordinado a ella.

Por otra parte, si el individuo sólo puede pensarse a sí mismo como un ser racional dentro de la trama de lazos intersubjetivos que pertenecen a la comunidad, la validez del derecho no puede considerarse meramente hipotética, así como tampoco el resultado de un juicio simplemente problemático. En este punto, es preciso admitir que Fichte no consigue eliminar todas las ambigüedades de su propuesta. En principio, Fichte comprende la decisión de pertenecer a la sociedad humana como una libre decisión del individuo que luego condiciona su contingente aceptación de la ley jurídica. Por ese motivo, Fichte puede afirmar también que la validez del derecho es sólo hipotética o técnico-práctica. Sin embargo, esta caracterización del principio del derecho como un principio con validez puramente hipotética entra en conflicto con los presupuestos antropológicos de Fichte y también con los resultados de su deducción trascendental. De acuerdo con la concepción fichteana del hombre, no resulta tan evidente que su pertenencia a la comunidad sea susceptible de una decisión libre o contingente. El hombre es un ser frágil e indeterminado, que necesita desde un inicio el auxilio de los demás miembros de la comunidad. De acuerdo con los conceptos trascendentales de exhortación y reconocimiento, los vínculos con una comunidad de seres racionales parecen más bien constitutivos del Yo, y no una simple circunstancia externa que puede modificarse a voluntad. Por ese motivo, no resulta muy convincente la afirmación de Fichte, según la vol.08, nº.03, Rio de Janeiro, 2015.pp. 1481-1508 1505 
cual cada individuo decide libremente si quiere pertenecer a la sociedad humana o permanecer fuera de ella. La pertenencia a esa sociedad humana es una condición necesaria para la autoconciencia individual. Ahora bien, si un Yo sólo puede existir como un ser racional dentro de una comunidad fundada en el derecho, y sólo puede cumplir en el interior de esa misma comunidad con las exigencias prácticas de la razón (establecidas por la ética bajo la forma de un imperativo), entonces quizás pueda afirmarse que el principio del derecho no sólo tiene una validez hipotética, sino también absoluta e incondicionada. El principio fichteano del derecho me exigiría entonces reconocer al otro como un ser racional y libre de manera categórica, porque en última instancia nunca puedo pensarme a mí mismo como un ente aislado de la relación que necesariamente mantengo con los demás seres racionales en el marco jurídico de una comunidad.

\title{
OBSERVATIONS ON THE VALIDITY OF THE PURE CONCEPT OF LAW IN GRUNDLAGE DES NATURRECHTS (1796/97) BY J. G. FICHTE
}

\begin{abstract}
:
It is really problematic the relationship between ethics and right within the Fichte's philosophy. On one hand, the ethical doctrine of Fichte is based on a principle with absolute and unconditional validity. As it happens in the critical philosophy of Kant, Fichte's moral law has the form of a categorical imperative, which demands obedience to all rational beings in any condition or circumstances. The Fichte's doctrine of natural right has a different basis. The principle of right demands a reciprocal relationship between rational beings, where everyone is able to limit their own freedom in favor of the possible freedom of others. In a first moment, Fichte says that the validity of this principle is merely hypothetical, because it only depends on the individual decision to live within a community. However, Fichte himself says later that it is almost impossible to imagine a human life outside of this intersubjective relationships whitin a community. The necessary relationship between the individual and the community is a fundamental premise of Fichte's philosophy. From this premise one can deduce many important theoretical implications. If a rational being only can be considered as such in the context of a community (when this community is based on the juridical law), it should be attributed also a categorical validity to the principle of right.
\end{abstract}

Keywords: right, individual, community, hypothetical validity, categorical validity.

\section{BIBLIOGRAFÍA}

BAUR, Michael (2006), Fichte's Impossible Contract, en Rights, Bodies and Recognition. New Essays on Fichte's Foundations of Natural Right, Tom Rockmore y Daniel Breazeale (eds.), London: Ashgate, pp. 11-25.

BINKELMANN, Christoph (2007), Theorie der praktischen Freiheit. Fichte-Hegel, Berlin-NewYork: Walter de Gruyter. 
DÜSING, Edith (1997), Individuelle und soziale Bildung der Ich-Identität. Fichtes Konzeption im Horizont moderner Alternativen en Fichte-Studien, 11, pp. 113-132.

FICHTE, Johann Gottlieb (1962 ss), Gesamtausgabe der Bayerischen Akademie der Wissenschaften, Lauth, R. Jacob, H. y Gliwitzky, H. (eds.), Stuttgart/Bad Cannstatt: Frommann-Holzboog.

HONNETH, Axel (1996): The Struggle for Recognition. The Moral Grammar of Social Conflicts, Cambridge: The Mit Press.

Honneth, Axel (2001), Die transzendentale Notwendigkeit von Intersubjektivität (Zweiter Lehrsatz: $₫$ 3), en Johann Gottlieb Fichte. Grundlage des Naturrechts, Jean-Christophe Merle (ed.), Berlin: Akademie Verlag, pp. 63-80.

IVALDO, Marco (2003), Fichte und Leibniz zur Intersubjektivität, en Fichte-Studien, 22, pp. 59-73.

KANT, Immanuel (1902 ss.), Kant's gesammelte Schriften, Berlin: Königlich Preußischen Akademie der Wissenschaften.

MATHER, Ronald (2003), On the Concepts of Recognition, en Fichte-Studien, 23, pp. 85-103.

NOWAK-JUCHACZ, Ewa (2003), Das Anerkennungsprinzip bei Kant, Fichte und Hegel, en Fichte-Studien, 23, pp. $75-84$.

RENAUT, Alain (1986), Le système du droit. Philosophie et droit dans le pensée de Fichte, Paris: Presses Universitaires de France.

RICHLI, Urs (1997), Das Wir in der späten Wissenschaftslehre, en Fichte-Studien, 12, pp. 351-363.

RIOBÓ GONZÁLEZ, Manuel (1988), Fichte, Filósofo de la Intersubjetividad, Barcelona: Herder.

SENIGAGLIA, Cristiana (2007), Die Strukturen der Intersubjektivität beim frühen Fichte en Christoph Asmuth (ed.) Transzendentalphilosophie und Person. Leiblichkeit- Interpersonalität- Anerkennung., Bielefeld: Transcript Verlag, pp. 163-177.

SIEMEK, Marek J. (1997), Wissen und Tun. Zur Handlungsweise der transzendentalen Subjektivität in der ersten Wissenschaftslehre Fichtes, en Fichte-Studien, 10, pp. 241-252.

Siemek, Marek J. (2003), Fichtes und Hegels Konzept der Intersubjektivität, en Fichte-Studien, 23, pp. 57-75.

SIEP, Ludwig (1978), Anerkennung als Prinzip der praktischen Philosophie, Freiburg: Alber Verlag.

WAIBEL, Violetta L. (2006), On the Fundamental Connection between Moral Law and Natural Right in Fichte's Contribution (1793) and Foundations of Natural Right (1796/97), en Rights, Bodies and Recognition. New Essays on Fichte's Foundations of Natural Right, Tom Rockmore y Daniel Breazeale (eds.), London: Ashgate, pp. 45-58. 
WILLIAMS, Robert R. (2006), Recognition, Right, and Social Contract, en Rights, Bodies and Recognition. New Essays on Fichte's Foundations of Natural Right, Rockmore, Tom y Breazeale, Daniel (eds.), London: Ashgate, pp. 26-44.

WOOD, Allen W. (2006), Fichte's Intersubjective I, en Inquiry, 49, 1, pp. $62-79$.

ZÖLLER, Günter (2007): Die zweite Person. Fichtes systematischer Beitrag, en Christoph Asmuth (ed.) Transzendentalphilosophie und Person. Leiblichkeit- Interpersonalität- Anerkennung., Bielefeld: Transcript Verlag, pp. 125-145.

Trabalho enviado em 14 de junho de 2015.

Aceito em 20 de julho de 2015. 